\title{
Pancreatic cancer in Brazil: mortality trends and projections until 2029
}

\author{
Isabelle Ribeiro BARBOSA, Camila Alves dos SANTOS and Dyego Leandro Bezerra de SOUZA
}

Received 8/2/2018

Accepted 31/7/2018

\begin{abstract}
Background - Pancreatic cancer is one of the main cancer-related causes of death in developed countries, and one of the most lethal malignant neoplasms. This type of cancer is classified as the ninth most frequent in the world. Objective - Analyze temporal trends for pancreatic cancer in Brazil in the period 2000-2014 and calculate mortality projections for the period 2015-2029. Methods - Ecological study, with temporal series, based on information provided by the Brazilian Mortality Information System. Analysis included deaths due to pancreatic malignant neoplasms in Brazil in the period 2000-2014, and analyzed according to sex, age group and Brazilian geographic regions. Projections were made until 2029 in five-year periods, calculated in Nordpred (within the R software). Mortality trends were analyzed by Joinpoint regression. Results - Between 2000 and 2014 , there were 112,533 deaths due to pancreatic cancer in Brazil. Age-standardised rates was 5.1 deaths/100,000 men and 3.81 deaths/100,000 women. The highest rates were registered for the Midwest region, for both genders. Projections indicated that for the five-year period 2025-2029 there will be increased mortality rates for men in the Northeast and Midwest regions. Joinpoint analysis for Brazil did not reveal significant increases for women $(\mathrm{APC}=0.4 \% ; 95 \% \mathrm{CI}:-0.2 ; 1.0)$, however, there was a significant increasing mortality trend for men (APC $=3.7 \%$; $95 \% \mathrm{CI}: 0.6-7.0)$ in the period 2000 2004 , followed by a stable period, an then another period of significant increases after 2010. These figures are mostly explained by variations in the Brazilian demographic structure. Conclusion - Pancreatic cancer mortality is unequally distributed across Brazilian regions and genders, and during the next two decades the differences will be accentuated.
\end{abstract}

HEADINGS - Pancreatic neoplasms. Mortality. Forecasting. Demography.

\section{INTRODUCTION}

Pancreatic cancer is one of the main cancer-related causes of death in developed countries, and one of the most lethal malignant neoplasms in the world ${ }^{(1)}$. Considering the year 2012,337 thousand people were diagnosed with pancreatic cancer in the world, while 330 thousand people died because of this disease. This type of cancer is classified as the ninth most frequent in the world, despite its rarity. Due to its high mortality rates, pancreatic cancer is the seventh cancer-related cause of death in the world ${ }^{(2)}$.

The symptoms of pancreatic cancer are initially insidious and gradually progress over time, including epigastric pain with or without posterior irradiation, weight loss, discomfort, nausea and fatigue. Jaundice is a characteristic sign of cancers in the head of the pancreas, due to the compression of the common bile duct. Sometimes a tumor can extend to the duodenum or stomach, leading to the obstruction of the gastric outlet ${ }^{(3)}$.

The two main types of pancreatic cancer are adenocarcinoma (responsible for $85 \%$ of cases) and pancreatic endocrine tumors (which represent less than $5 \%$ of cases) ${ }^{(1)}$. Only $10 \%-10 \%$ of patients are diagnosed in initial stages, when surgical resection can be an option. More than $90 \%$ of individuals are diagnosed in advanced stages. Due to the bad prognosis and late treatment, the survival rates during the first year of diagnosis is very low $(10 \%-20 \%)$ and decreases to $5 \%$ in the fifth year ${ }^{(4)}$.

Currently there are no adequate, safe, effective and sensible monitoring strategies in terms of costs, to be implemented for the general population, even for those with significant risk factors, such as exposure to tobacco and advanced age $\mathrm{e}^{(5)}$. Moreover, environmental and genetic factors contribute to the etiology of pancreatic cancer. Individuals with family history of pancreatic cancer have a higher risk of developing the disease and this risk increases with the number of first-degree relatives affected. Family history is related to germinal mutations in genes CDKN2A, BRCA2, PALB2, STK11 and PRSS1, which have been demonstrated to increase the risk of developing pancreatic cancer ${ }^{(6)}$.

The consumption of tobacco is the most consistently risk factor established for pancreatic cancer, contributing to $25 \%$ of cases. Other suspected risk factors include the excessive consumption of alcohol, chronic pancreatitis, and dietary-endocrine factors ${ }^{(7)}$. Emerging molecular studies suggest that the carcinogenic effect of hyperglycemia, the mitogenic effect of hyperinsulinemia associated with obesity and chronic inflammation in diabetes can be considered as risk factors involved in the proliferation and metastasis of pancreatic cancer ${ }^{(8)}$.

Pancreatic cancer occurs at all ages, but the incidence peak occurs between 60 and 80 years of age. Less than $10 \%$ of cases occur in individuals under the age of 55, and the average onset age is 71 years $^{(3)}$. Pancreatic cancer rates are considerably higher in the Afro-American population than in any other racial group. Men present higher incidence rates than women ${ }^{(9)}$.

As a disease with remarkable mortality, comprehension of the geographic distribution of pancreatic cancer and the behavior of rates throughout time is important, as the analysis of the epidemiological situation is necessary to support the planning of public 
health measures for vulnerable groups. To this date, few studies have examined the epidemiology of pancreatic cancer in South America, especially in Brazil. Therefore, the objective of the study presented herein is to analyze the temporal trends of pancreatic cancer in Brazil and its geographic regions in the period 2000-2014 and calculate mortality projections for the period 2015-2029.

\section{METHODS}

A temporal series, ecological study was carried out, based on secondary data registered by the Brazilian Mortality Information (SIM), made available by the Informatics Department of the Unified Health System (Brazil's publicly funded healthcare system). Analysis included deaths due to pancreatic malignant neoplasms (C25) categorized from the International Statistical Classification of Diseases and Related Health Problems - 10th revision (ICD-10) occurred in Brazil in the period 2000-2014, and analyzed according to sex, age group and Brazilian geographic regions.

Although within recent years it is recognized that SIM experimented a significant improvement in quality, the utilization of secondary data on mortality is subject to under-registry. For the correction of under-registered deaths by pancreatic cancer, information was obtained from the Redistribution of the Deaths per Chapters, corrected by Active Search Investigation, an initiative of the Ministry of Health, with data provided by the Informatics Department of the Unified Health System.

The correction factor was calculated for each age group, period, region and sex, from the percentage difference between the amount of deaths reported to SIM and redistributed deaths, based on Chapter II (Neoplasms) of ICD-10. The difference (D) was expressed in decimal values with 1 corresponding to a $100 \%$ change, with the possibility of obtaining values higher than 1 as some locations presented redistributed values above those reported to SIM (Equation 1). When the redistributed value was less than what was reported to SIM, a negative difference was obtained.

$$
\mathrm{D}=\frac{\mathrm{NR}-\mathrm{NS}}{\mathrm{NS}}
$$

In Equation 1, NR is the number of redistributed deaths by neoplasms, and NS is the number of neoplasm-related deaths reported to SIM.

The difference obtained (D) was added to the value 1 to establish a correction value (F, in agreement with Chapter II - neoplasms), as the number 1 represents a neutral factor in a multiplication, according to Equation 2:

$$
\mathrm{F}=1+\mathrm{D}
$$

Factor $\mathrm{F}$ was then multiplied by the number of deaths by suicide. It was assumed that the correction factor for Chapter II was applicable to pancreatic cancer, as shown by Equation 3:

$$
\mathrm{OC}=\mathrm{F} \times \mathrm{NOS}
$$

In equation $3, \mathrm{OC}$ is the corrected number of deaths due to pancreatic cancer, and NOS is the number of deaths due to pancreatic cancer reported to SIM.

With information on the readjusted number of deaths, standardized mortality rates were calculated, adjusted to the world population, per 100,000 inhabitants ${ }^{(10)}$. Population data by region, sex and age were obtained from demographic censuses and inter- census projections, available at the website of the Brazilian Institute of Geography and Statistics.

The temporal trends of pancreatic cancer mortality in Brazil and its geographic regions were analyzed, and projections were made until 2029 in five-year periods (2015-2019, 2020-2024 and 2025-2029).

Analysis of mortality trends utilized Joinpoint regression, with software Joinpoint Regression Program (National Cancer Institute, Bethesda, Maryland, USA), version 4.4.0. The objective of the analysis is to identify the occurrence of possible joinpoints, where significant changes in trends occurred.

The applied method identified joinpoints based on the model with up to three change points. The final model selected was the most adjusted method, with Annual Percentage Change (APC) based on the trend of each segment, estimating whether these values were statistically significant to a 0.05 level. The significance tests utilized were based on the Monte Carlo permutation method and on the calculation of the annual percentage variation of the ratio, utilizing the logarithm of the ratio.

In the description of trends, the terms "significant increase" or "significant decrease" mean that the slope of the trend is statistically significant $(P<0.05)$.

Predictions were made for each period utilizing the ageperiod-cohort model of the Nordpred program (Cancer Registry of Norway, Oslo, Norway), within statistical program R. Data were compiled in five-year blocks. The results of the predictions are presented for the total of observed and expected deaths for each period in Brazil and its five geographic regions. For each period, adjusted mortality rates were calculated based on the agestandardised rates $(\mathrm{ASR})^{(10)}$.

The annual changes in the number of deaths were calculated for the last projected period (2025-2029) in comparison with the last observed period (2010-2014), where the proportion of this change could be due to risk of die due to pancreatic cancer or due to demographic changes (size or structure of population). These two components could be different from zero and present a positive or negative direction. Calculation follows Equation $4^{(11)}$ :

$$
\Delta_{t o t}=\Delta_{r i s k}+\Delta_{p o p}=\left(N_{f f f}-N_{o f f}\right)+\left(N_{o f f}-N_{o o o}\right)
$$

$\Delta$ tot is the total change, $\Delta$ risk is the change in function of risk, $\Delta$ pop is the change in function of population, Nooo is the number of observed cases, Nfff is the number of projected cases and Noff is the number of expected cases when mortality rates increase during the observed period.

\section{RESULTS}

Between 2000 and 2014, there were 112,533 deaths due to pancreatic malignant neoplasms in Brazil, with $50.2 \%$ of deaths affecting male individuals and $49.8 \%$ affecting females. The standardized mortality rates to the world population for Brazilian men varied between 4.2 deaths $/ 100,000$ inhabitants in 2000 , to 5.1 deaths $/ 100,000$ inhabitants in 2014 . For women, rates varied between 3.6 deaths $/ 100,000$ inhabitants in 2000 to 3.81 deaths $/ 100,000$ inhabitants in 2014. The highest mortality rates were registered for the Midwest region, for both sexes. High mortality rates in men of the Southeast region should also be highlighted (FIGURE 1).

Joinpoint analysis for Brazil did not reveal significant increases for mortality in the female sex (APC $=0.4 \% ; 95 \% \mathrm{CI}:-0.2 ; 1.0$ ), however, there was a significant increasing mortality trend for men 


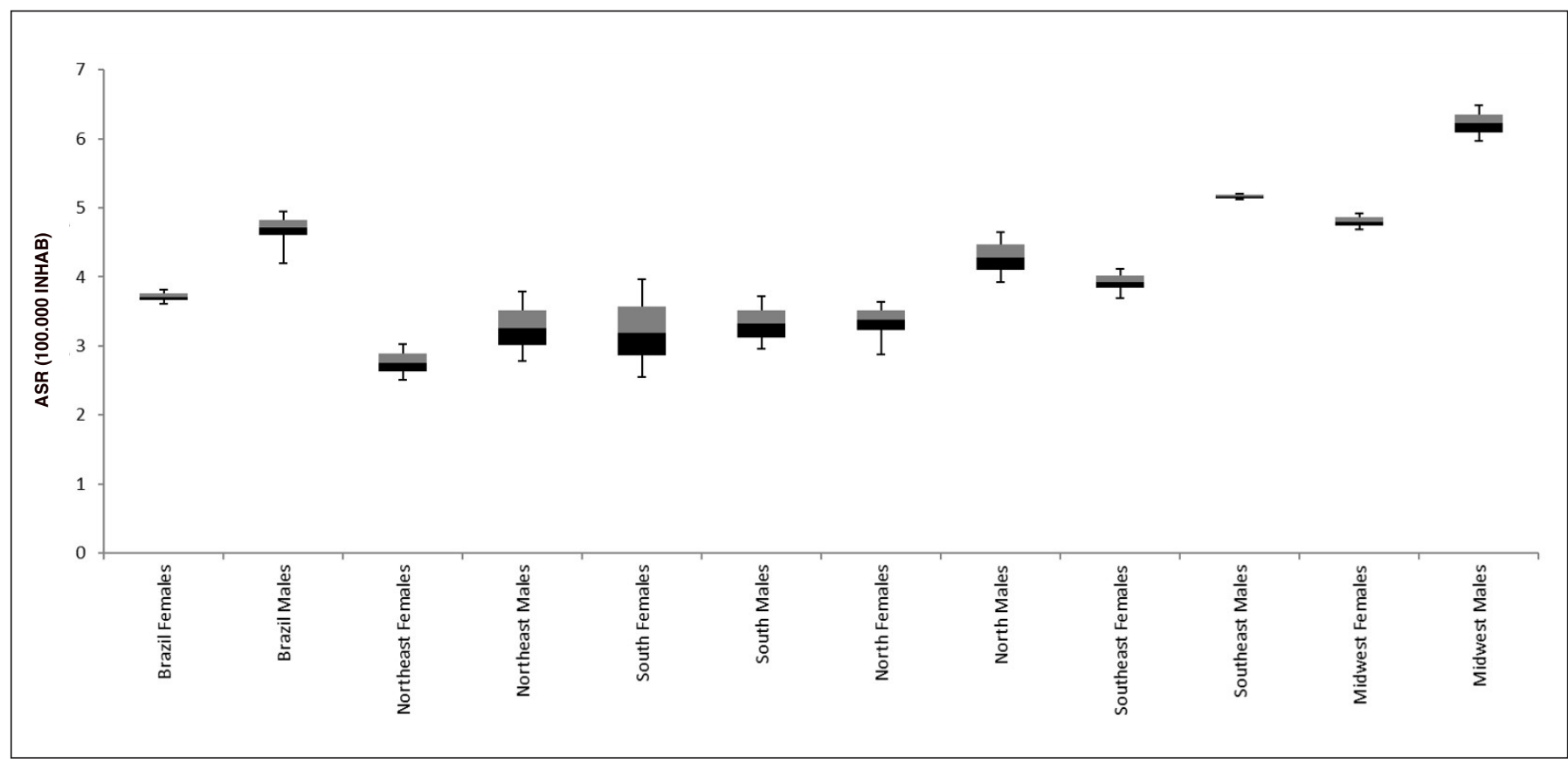

FIGURE 1. Standardized pancreatic cancer mortality rates for Brazil and its geographic regions, according to sex, for the period $2000-2014$. Brazil, 2017.

$(\mathrm{APC}=3.7 \% ; 95 \% \mathrm{CI}: 0.6-7.0)$ in the period 2000-2004, followed by a stable period, an then another period of significant increases after 2010. The Northeast region registered a significant increase in female $(\mathrm{APC}=1.4 \%$; 95\% CI: 0.2-2.6) and male $(\mathrm{APC}=2.3 \%$; 95\% CI: 1.4-3.3) mortalities. For the Midwest region, the female sex presented two joinpoints: a significant increasing period until $2004(\mathrm{APC}=6.2 \%)$, followed by a stable period $(\mathrm{APC}=-2.5 \%)$, and then in 2010 a period of significant increase (APC $=4.2 \%$ ) occurred. The North and South regions did not present significant trends for either sexes (TABLE 1).
TABLE 2 and TABLE 3 presents the number of deaths and standardized mortality rates for the observed and projected periods, for women and men, respectively. Data analysis for Brazil for the five-year period 2025-2029 resulted in the expected occurrence of 38,551 and 41,952 deaths in females and males, respectively, due to pancreatic cancer. Mortality rates for females will not present considerable increases in the future; Brazilian, Midwest and North regional rates will present decreasing rates throughout the period. For the male sex, the same behavior will be observed, but the Northeast and Midwest rates will present increasing trends until 2029.

TABLE 1. Temporal trends for pancreatic cancer mortality in Brazil.

\begin{tabular}{|c|c|c|c|c|c|c|}
\hline & Number of Deaths & APC1 $(95 \%$ CI) & Joinpoint & APC2 $(95 \%$ CI) & Joinpoint & APC3 $(95 \% \mathrm{CI})$ \\
\hline Brazil & 56,066 & $0.4(-0.2 ; 1.0)$ & & & & \\
\hline Northeast & 10,894 & $1.4 *(0.2-2.6)$ & & & & \\
\hline North & 1960 & $-3.1(-8.0-1.8)$ & & & & \\
\hline South & 11,600 & $0.4(-1.0-1.3)$ & & & & \\
\hline \multicolumn{7}{|l|}{ Males } \\
\hline Brazil & 56,517 & $3.7 *(0.6-7.0)$ & 2004 & $-1(-2.9-0.9)$ & 2010 & $2.7 *(0.2-5.2)$ \\
\hline Northeast & 10,411 & $2.3 *(1.4-3.3)$ & & & & \\
\hline South & 11,844 & $0.6(-0.1-1.3)$ & & & & \\
\hline
\end{tabular}

*Statistically significant $\mathrm{P}<0.05$. APC: annual percentage change; $\mathrm{CI}$ : confidence intervals. 
TABLE 2. Pancreatic cancer mortality in females, for Brazil and its geographic regions.

\begin{tabular}{lcccccc}
\hline & \multicolumn{5}{c}{ Observed } & \multicolumn{3}{c}{ Projected } \\
\cline { 2 - 7 } & $2000-$ & $2005-$ & $2010-$ & $2015-$ & $2010-$ & $2025-$ \\
\hline Brazil & & & & & & \\
Age (yr) & & & & & & \\
0-54 & 22604 & 2009 & 2014 & 2019 & 2024 & 2029 \\
55-74 & 6986 & 8361 & 10265 & 12909 & 15782 & 18386 \\
$\geq 75$ & 5627 & 7165 & 9202 & 10356 & 12663 & 15900 \\
ASR & 2.58 & 3.06 & 2.72 & 2.36 & 2.09 & 1.89 \\
\hline Northeast & & & & & & \\
Age (yr) & & & & & & \\
0-54 & 494 & 591 & 728 & 925 & 1037 & 1097 \\
$55-74$ & 1349 & 1565 & 1969 & 2384 & 2886 & 3419 \\
$\geq 75$ & 1043 & 1351 & 1804 & 2021 & 2514 & 3083 \\
ASR & 2.62 & 2.75 & 2.90 & 3.02 & 3.08 & 3.10 \\
\hline
\end{tabular}

North

Age (yr)

$\begin{array}{lllllll}0-54 & 122 & 170 & 162 & 147 & 138 & 142\end{array}$

$\begin{array}{lllllll}55-74 & 211 & 318 & 354 & 400 & 441 & 476\end{array}$

$\begin{array}{lllllll}\geq 75 & 148 & 205 & 263 & 295 & 357 & 445\end{array}$

$\begin{array}{lllllll}\text { ASR } & 2.58 & 3.06 & 2.72 & 2.36 & 2.09 & 1.89\end{array}$

Midwest

$\begin{array}{lllllll}\text { Age }(\mathrm{yr}) & & & & & & \\ 0-54 & 128 & 169 & 214 & 264 & 296 & 328 \\ 55-74 & 334 & 429 & 585 & 773 & 984 & 1203 \\ \geq 75 & 215 & 289 & 403 & 498 & 682 & 928 \\ \text { ASR } & 3.31 & 3.32 & 3.43 & 3.43 & 3.45 & 3.45\end{array}$

Southeast

Age (yr)

$\begin{array}{lllllll}0-54 & 1099 & 1386 & 1567 & 1753 & 1795 & 1895\end{array}$

$\begin{array}{lllllll}55-74 & 3579 & 4152 & 5115 & 6519 & 8027 & 9336\end{array}$

$\begin{array}{lllllll}\geq 75 & 2925 & 3775 & 4718 & 5335 & 6400 & 8021\end{array}$

$\begin{array}{lllllll}\text { ASR } & 3.93 & 3.94 & 3.95 & 3.95 & 3.98 & 4.01\end{array}$

South

Age (yr)

$\begin{array}{lllllll}0-54 & 399 & 553 & 616 & 699 & 713 & 731\end{array}$

$\begin{array}{lllllll}55-74 & 1411 & 1828 & 2173 & 1945 & 3374 & 3920\end{array}$

$\begin{array}{lllllll}\geq 75 & 1170 & 1484 & 1957 & 2289 & 2853 & 3655\end{array}$

$\begin{array}{lllllll}\text { ASR } & 4.58 & 4.90 & 4.86 & 4.85 & 4.85 & 4.87\end{array}$

ASR: age-standardised rates.
TABLE 3. Pancreatic cancer mortality in males, for Brazil and its geographic regions.

\begin{tabular}{ccccccc}
\hline & \multicolumn{3}{c}{ Observed } & \multicolumn{3}{c}{ Projected } \\
\cline { 2 - 7 } & $\begin{array}{c}2000- \\
2004\end{array}$ & $2005-$ & $2010-$ & $2015-$ & $2010-$ & $2025-$ \\
& & & & & & \\
\hline Brazil & & & & & & \\
Age (yr) & & & & & & \\
$0-54$ & 3301 & 3966 & 4429 & 7912 & 4626 & 5139 \\
$55-74$ & 7595 & 9394 & 11739 & 11533 & 15112 & 21030 \\
$\geq 75$ & 4152 & 5249 & 6692 & 7347 & 7541 & 15783 \\
ASR & 4.52 & 4.73 & 4.84 & 4.89 & 4.89 & 4.82 \\
\hline
\end{tabular}

Northeast

Age (yr)

\begin{tabular}{lcccccc}
$0-54$ & 577 & 749 & 876 & 1027 & 1103 & 1210 \\
$55-74$ & 1255 & 1662 & 2103 & 2596 & 3134 & 3581 \\
$\geq 75$ & 858 & 1033 & 1297 & 1319 & 1663 & 2093 \\
ASR & 2.92 & 3.36 & 3.54 & 3.70 & 3.77 & 3.75 \\
\hline
\end{tabular}

North

Age (yr)

\begin{tabular}{lllllll}
$0-54$ & 184 & 224 & 229 & 260 & 264 & 284 \\
$55-74$ & 291 & 367 & 502 & 656 & 811 & 918 \\
$\geq 75$ & 149 & 179 & 254 & 257 & 345 & 479 \\
ASR & 3.19 & 3.26 & 3.45 & 3.52 & 3.50 & 3.39 \\
\hline
\end{tabular}

Midwest

Age (yr)

\begin{tabular}{lcccccc}
$0-54$ & 206 & 257 & 296 & 359 & 377 & 402 \\
$55-74$ & 427 & 511 & 750 & 1055 & 1397 & 1686 \\
$\geq 75$ & 187 & 264 & 396 & 485 & 651 & 883 \\
ASR & 4.08 & 4.10 & 4.56 & 4.92 & 5.13 & 5.14 \\
\hline
\end{tabular}

Southeast

Age (yr)

\begin{tabular}{lllllll}
$0-54$ & 1707 & 1972 & 2138 & 2284 & 2266 & 2325 \\
$55-74$ & 3883 & 4742 & 5767 & 7428 & 8937 & 10085 \\
$\geq 75$ & 2048 & 2596 & 3322 & 3738 & 4691 & 6146 \\
ASR & 5.09 & 5.18 & 5.19 & 5.16 & 5.08 & 4.98 \\
\hline
\end{tabular}

South

Age (yr)

\begin{tabular}{lllllll}
$0-54$ & 600 & 751 & 872 & 997 & 1002 & 985 \\
$55-74$ & 1659 & 2058 & 2567 & 3344 & 4113 & 4729 \\
$\geq 75$ & 836 & 1127 & 1376 & 1609 & 2056 & 2682 \\
ASR & 5.99 & 6.29 & 6.36 & 6.43 & 6.48 & 6.51 \\
\hline
\end{tabular}

ASR: age-standardised rates. 
FIGURE 2 presents mortality rates due to pancreatic cancer, for the observed and projected periods, according to the influence of risks and population structure of Brazil and its regions. This calculation showed that there will be an increase in mortality rates, and these numbers are mainly explained by variations in the Brazilian demographic structure for all Brazilian geographic regions and for both sexes. For females, the reduction of risks must be highlighted along with the positive influence of demographic changes to explain the increase in the number of deaths in the future.

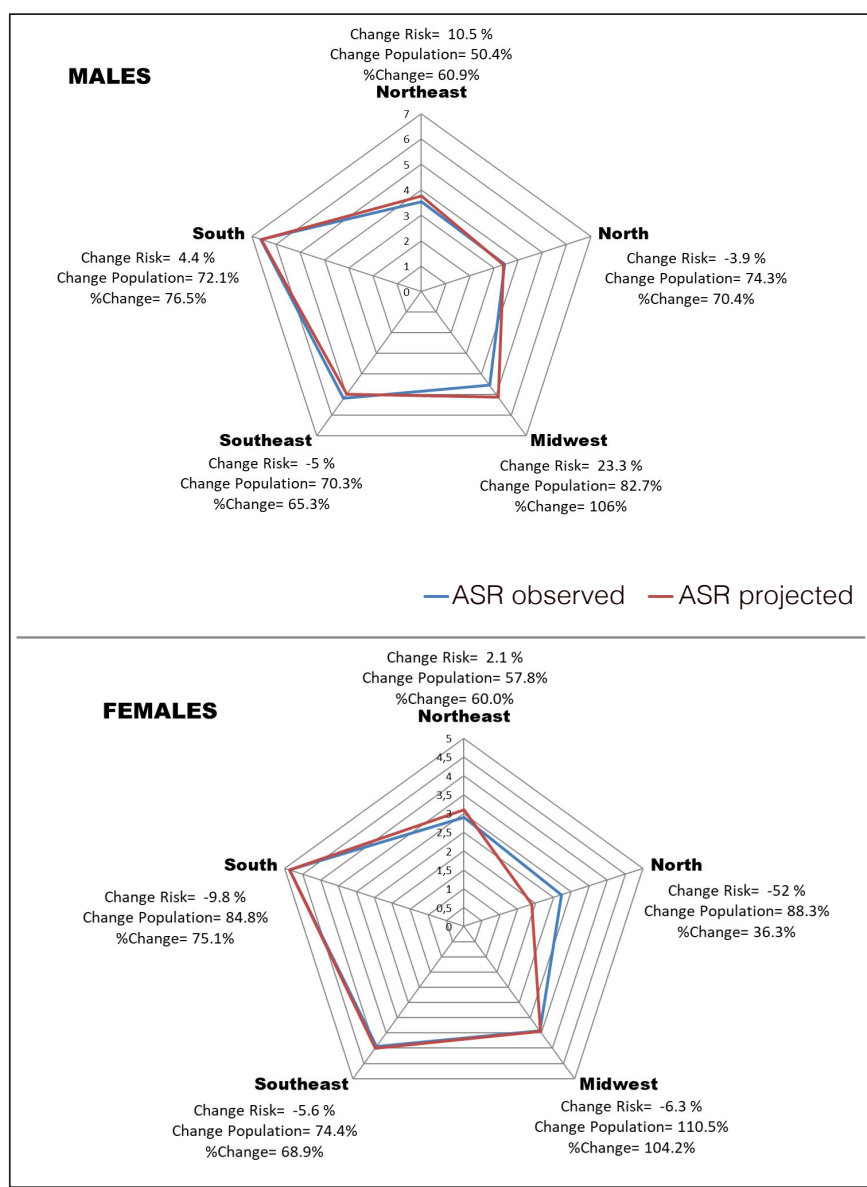

FIGURE 2. Age-standardised rates (ASR) total change (change), relative change due to risk (risk) and changed population (pop), between 2010-2014 (observed) and 2025-2029 (predicted) for pancreatic cancer mortality in Brazil.

\section{DISCUSSION}

Increasing trends were verified for pancreatic cancer mortality in Brazil throughout the period comprehended between 2000 and 2014, with important regional variations and higher rates for the male sex. When compared with the highest and lowest rates in the world, the Brazilian mortality rates for pancreatic cancer were intermediate: North America and Eastern Europe present 6.9 and 6.8 deaths/100,000 inhabitants, respectively, and South Africa and Central Asia present under 1.0 death/100,000 inhabitants ${ }^{(1,12)}$.

Pancreatic cancer is more frequent in men. The ratio between sexes, in general, is 6:1 in developed countries and 1:1 in developing countries. Globally, approximately 173,000 deaths occur due to pancreatic cancer in men, with 156,000 deaths in women. In developed countries, mortality rates are 7-9/100,000 in men and 4,5-6/100,000 in women ${ }^{(2,13)}$. The results presented herein showed that Brazilian mortality rates follow the behavior observed in developed countries.

As verified herein for Brazil, in several parts of the world increasing trends were also observed for pancreatic cancer mortality. Serbia, one of the countries with the highest pancreatic cancer mortality rates in the world, presented increasing trends for both sexes in the period 1991-2010, with $1.6 \%$ annual growth $(95 \% \mathrm{CI}$ : 1.1-2.0) for men and 2.2\% (95\% CI: 1.7-2.7) for women ${ }^{(14)}$. In Korea, pancreatic cancer increased considerably between 1983 and 1994, with $\mathrm{APC}=9.82 \%$ in men and $12.57 \%$ in women ${ }^{(15)}$. In Canada, analysis of mortality trends between 1992 and 2005 revealed a 7\% decrease in standardized mortality, per age group, in men (from $11.18 / 100,000$ in 1992 to $10.38 / 100,000$ in 2004) and a $3 \%$ increase in women (from $7.98 / 100,000$ in 1992 to $8.23 / 100,000$ in 2004) ${ }^{(16)}$. In Italy, increasing trends were observed for the female sex only (APC $=0.7 \%$ from 1989 to 2010$)^{(17)}$.

Regarding pancreatic cancer, long term survival rates remain very low, despite improvements in recent decades. One-year survival for patients improved between 1981 and 2010, from $17.0 \%$ to $19.9 \%$, and then to $28.2 \%$, with a $42 \%$ increase when comparing the second and third decades. This indicates a general progress in the epidemiology of this cancer, either due to early diagnosis or improvements in treatment and care. However, five-year survival increased from $3.1 \%$ to $4.4 \%$, and then to only $6.9 \%$ throughout the last thirty years; i.e., only few patients affected by pancreatic cancer survive for more than five years after resection ${ }^{(18)}$.

The variation in incidence and mortality rates for pancreatic cancer around the world can be an indicator of differences in the prevalence of several risk factors, between sexes and between races, which in turn are a result of different levels of development across countries ${ }^{(9)}$. The hypotheses drawn to explain this include the fact that female steroid hormones could play a protective role. There are also several risk factors with established prevalence (e.g., consumption of tobacco, diabetes and heredity) and other still not elucidated (e.g., excessive ingestion of alcohol, high body mass index), which are under consideration to explain racial differences in pancreatic cancer incidence. However, further research is still required to determine the extension of genetic contribution and other factors towards the differences detected in pancreatic cancer incidence in men and women, and in different races ${ }^{(18)}$.

In Brazil, the prevalence of the main risk factors related to pancreatic cancer were estimated by the National Health Survey, carried out in 2013, which revealed that the prevalence of diabetes and consumption of tobacco in the population were, respectively, $6.2 \%(19)$ and $15 \%{ }^{(20)}$. The Telephone Survey Vigilance System for Risk Factors and Protection regarding chronic diseases (Vigitel) verified that the prevalence of obesity and overweight were, respectively, $15.8 \%$ and $48.5 \%$ in the Brazilian population ${ }^{(21)}$. For all these studied factors, it was also observed that the Brazilian population presents different exposure patterns, where prevalence vary across regions and according to sociodemographic characteristics, which could explain the pancreatic cancer mortality patterns observed herein.

It is also important to consider that international differences in incidence and mortality rates could reflect the capacity of diagnosis and changes in the utilization of several types of diagnosis techniques. In 2012, Europe represented a third of global incidence, 
probably reflecting a more precise diagnosis of pancreatic cancer. It must be highlighted that a share of incidence and mortality differences across countries could also be attributed to the quality of registries, with variable coverage, integrity and precision ${ }^{(1)}$.

Early detection of pancreatic cancer through radiographic images and high resolution endoscopic ultrasound has increased sensitivity regarding the detection of lesions, although conventional tomographies also provide detailed views of pancreatic tumors in relation to the superior mesenteric artery, celiac axis, superior mesenteric vein, and portal vein. This image technique is still the preferred choice for initial evaluation of the majority of patients with suspected pancreatic cancer ${ }^{(22)}$. Besides the currently utilized serologic markers, new markers, including those obtained from tumor blood or tissue, are being evaluated for early or more precise detection and prediction ${ }^{(23)}$.

In general, screening programs involve multidisciplinary specialist teams and a combination of image techniques, usually based on endoscopic ultrasound. However, data have not generated a widely accepted screening protocol. Consensus practice recommendations, based mostly on the opinion of specialists, suggest a risk threshold increased 10 times to select the individuals that could benefit from screening, but this threshold excludes patients with significant risk (increases between 5 and 10 times). Results and cost efficiency analyses were also not currently possible, due to the lack of uniform screening practices. Although counseling and genetic tests were recommended as a part of the treatment of selected patients, there is little published information on the impact of genetic tests on these patients ${ }^{(5)}$. There are no current screening recommendations for pancreatic cancer, and therefore primary prevention of risk factors is paramount.

Although Brazil presents intermediate mortality rates, the structure and organization of health services could be predictors of the mortality rates observed in the country. In Latin America (e.g., Brazil, Mexico), large urban centers concentrate the majority of oncology services, as a consequence of extreme internal migration and development of these areas due to regional and local socioeconomic demands. The populations of rural areas must travel to large urban centers to receive treatment, consult with specialists and be assisted by diagnosis centers. These difficulties generate delays in diagnosis and treatment of patients, which results in worse prognosis in comparison with patients that already reside in urban centers ${ }^{(24)}$.

This particular situation can explain the inequalities observed in the mortality rates across Brazilian geographic regions, where increasing trends were verified for the poorest regions of the country, such as the Northeast. In Brazil, the distribution of hierarchic levels for patient care is unequal, with high disparities: areas with better urban structures (Southeast and South regions), count with well-equipped and distributed health systems, while the North and Northeast regions suffer with the absence of intermediate hierarchic levels. Besides the traditional concentration of equipment and services, with scarce intermediate-level healthcare centers (as occurs in the Northeast), the North region is also affected by a scarce occupation of the territory, which is negatively reflected on the organization and distribution of the offer of health services $^{(25,26)}$. The unequal allocation of resources, concentration of health professionals in urban centers, and the lack of investments in resources and infrastructure lead to the reproduction of socioeconomic inequalities in the assistance of individuals with cancer ${ }^{(24)}$.
Our prediction model for Brazil estimated that, in 2025-2029, pancreatic cancer will be responsible for 38,551 deaths in women and 41,952 deaths in men. Besides Brazil, other countries have also demonstrated the impact of this type of cancer in future mortality. Projections carried out for Switzerland estimate that in 2025-2029, pancreatic cancer could be the main cause of deaths related to gastrointestinal cancers ${ }^{(27)}$. In Canada, the result is similar: it is expected that, in 2031, the number of cases of pancreatic cancer more than doubles, as a result of an exponential increase in the population over the age of $65^{(16)}$. Cancer mortality projections for the U.S.A. show that, in 2030, pancreatic cancer will be one of the three main cancer-related causes of death, for men and women, with a predicted occurrence of 63,000 deaths in $2030^{(28)}$.

Any attempt to minimize the impact of pancreatic cancer mortality in Brazil must, in the future, also include adequate planning of services, besides the identification of reference centers, regionalization of treatment, reduction of distances travelled by patients and organization of treatment demands per region ${ }^{(29)}$. Although Brazil counts with an universal health system, the challenge for the next years will be the development of a system that is capable of responding to changes in health risks and in assistance necessities, due to the demographic changes that the country has been experiencing.

Addressing pancreatic cancer is a great challenge for the future. There is a clear necessity of investing in basic, translational and clinical research nowadays, as a preparation for the expected dramatic increase in mortality due to this type of cancer in the next 10-20 years. Changes in pancreatic cancer mortality rates require high investments in the comprehension and identification of early detection strategies and therapeutic targets that can be tested in clinical trials ${ }^{(29)}$. Also, new and more effective preventive measures oriented towards the main risk factors, such as obesity and tobacco consumption, could result in lower incidence and mortality risks (lower than those predicted).

One of the limitations of this study regards the national registry of deaths by cancer in Brazil. It must be mentioned that, in the past, there have been issues with data reliability, especially in the North and Northeast regions, but improvements have been implemented since the 2000's ${ }^{(30)}$.

\section{CONCLUSION}

In conclusion, data analysis showed an unfavorable epidemiological situation related to pancreatic cancer in Brazil, considering regional differences in the spatial distribution of cancer and also the increasing temporal trends observed in the last 15 years (which will continue throughout the next decades). The results of the projections clearly showed the inequalities embedded in pancreatic cancer mortality per geographic region, which must be considered in the development of public policies and planning of health services.

\section{Authors' contribution}

Barbosa IR, Santos CA and Souza DLB contributed to study conception and design; Barbosa IR contributed to data acquisition, data analysis and interpretation, and writing of article; Santos CA and Souza DLB contributed to editing, reviewing and final approval of article. 
Barbosa IR, Santos CA, Souza DLB. Câncer pancreático no Brasil: tendências e projeções da mortalidade até 2029. Arq Gastroenterol. 2018,55(3):230-6.

RESUMO - Contexto - O câncer de pâncreas é uma das principais causas de morte relacionadas ao câncer em países desenvolvidos, e uma das neoplasias malignas mais letais. Este tipo de câncer é classificado como o nono mais frequente do mundo. Objetivo - Analisar as tendências temporais do câncer de pâncreas no Brasil no período de 2000-2014, e calcular as projeções de mortalidade para o período de 2015-2029. Métodos - Estudo ecológico, de séries temporais, baseado em informações advindas do Sistema de Informações sobre Mortalidade brasileiro. A análise incluiu os óbitos por neoplasias malignas pancreáticas no Brasil, no período de 2000 a 2014, avaliados segundo sexo, faixa etária e regiões geográficas brasileiras. As projeções foram feitas até 2029, em períodos de cinco anos, calculados no Nordpred (no software R). E as tendências de mortalidade foram analisadas por regressão Joinpoint. Resultados - Entre 2000 e 2014, ocorreram 112.533 mortes por câncer de pâncreas no Brasil. A taxa padronizada foi de 5,1 mortes /100.000 homens e 3,81 mortes /100.000 mulheres. As maiores taxas foram registradas para a região Centro-Oeste, para os dois gêneros. As projeções indicaram que, para o quinquênio 2025-2029, haverá aumento nas taxas de mortalidade de homens nas regiões Nordeste e Centro-Oeste. A análise do joinpoint para o Brasil não revelou aumento significativo para as mulheres (APC $=0,4 \% ;$ IC95\%: $-0,2 ; 1,0)$, entretanto, houve um aumento significativo da tendência de mortalidade para homens (APC=3,7\%; IC95\%: 0,6-7,0) no período 2000-2004, seguido de um período de estabilidade e, em seguida, aumento significativo após 2010. Esses resultados são explicados principalmente por variações na estrutura demográfica brasileira. Conclusão - A mortalidade por câncer de pâncreas está distribuída de forma desigual nas regiões e gêneros brasileiros e, nas próximas duas décadas, as diferenças serão acentuadas.

DESCRITORES - Neoplasias pancreáticas. Mortalidade. Previsões. Demografia.

\section{REFERENCES}

1. Ilic M, Ilic I. Epidemiology of pancreatic cancer. World J Gastroenterol. 2016;22:9694-705.

2. Smiljana R, Mikov MM, Petrovic V, Jasna T, Tihomir D, Milanka T. Epidemiology of pancreatic cancer in vojvodina province in Serbia. Asian Pac J Cancer Prev. 2014;15:10779-82.

3. Ansari D, Tingstedt B, Andersson B, Holmquist F, Sturesson C, Williamsson C, Andersson R. Pancreatic cancer: yesterday, today and tomorrow. Future Oncol. 2016;12:1929-46.

4. Loc WS, Smith JP, Matters G, Kester M, Adair JH. Novel strategies for managing pancreatic cancer. World J Gastroenterol, 2014;20:14717-25.

5. Verna EC, Hwang C, Stevens PD, Rotterdam H, Stavropoulos SN, Sy CD, et al. Pancreatic cancer screening in a prospective cohort of high-risk patients: a comprehensive strategy of imaging and genetics. Clinical Cancer Research. 2010;16:5028-37.

6. Brune KA, Lau B, Palmisano E, Canto M, Goggins MG, Hruban RH, Klein AP. Importance of age of onset in pancreatic cancer kindreds. J Natl Cancer Inst. 2010;102:119-26.

7. Li D, Abbruzzese JL. New strategies in pancreatic cancer: emerging epidemiologic and therapeutic concepts. Clin Cancer Res. 2010;16:4313-8.

8. Er KC, Hsu CY, Lee YK, Huang MY, Su YC. Effect of glycemic control on the risk of pancreatic cancer: A nationwide cohort study. Medicine. 2016;95:e3921.

9. Yadav D, Lowenfels AB. The epidemiology of pancreatitis and pancreatic cancer. Gastroenterology. 2013;144:1252-61.

10. Doll R, Payne P, Waterhouse JAH. Cancer Incidence in Five Continents. Vol 1 Geneva, UICC: Berlin. Springer; 1966.

11. Møller B, Fekjaer H, Hakulinen T, Sigvaldason H, Storm HH, Talbäck M, Haldorsen T. Prediction of câncer incidence in the nordic countries: Empirical comparison of diferente approaches. Stat Med. 2003;22:2751-66.

12. Ferlay J, Steliarova-Foucher E, Lortet-Tieulent J, Rosso S, Coebergh JWW, Comber H, Bray F. Cancer incidence and mortality patterns in Europe: estimates for 40 countries in 2012. Eur J Cancer. 2013;49:1374-403.

13. Zeni LB, Russi RF, Fialho AF, Fonseca ALP, Sombrio LS, Rocha IC. Morbidity and mortality of pancreatic tumors undergoing surgical treatment. ABCD. Arq Bras Cir Dig. 2014;27:275-9.

14. Ilić M, Vlajinac H, Marinković J, Kocev N. Pancreatic cancer mortality in Serbia from 1991-2010-a joinpoint analysis. Croat Med J. 2013;54:369-75.

15. Lim D, Ha M, Song I. Trends in major cancer mortality in Korea, 1983-2012, with a joinpoint analysis. Cancer Epidemiol. 2015,39:939-46.

16. Flook R, van Zanten SV. Pancreatic cancer in Canada: incidence and mortality trends from 1992 to 2005. Can J Gastroenterol. 2009;23:546-50.
17. Rosso T, Bertuccio P, La Vecchia C, Negri E, Malvezzi M. Cancer mortality trend analysis in Italy, 1980-2010, and predictions for 2015. Tumori. 2015;101:664-75.

18. Sun H, Ma H, Hong G, Sun H, Wang J. Survival improvement in patients with pancreatic cancer by decade: a period analysis of the SEER database, 1981-2010. Sci Rep. 2014;4:6747.

19. Iser BPM, Stopa SR, Chueiri PS, Szwarcwald CL, Malta DC, Monteiro HODC, Schmidt MI. Prevalência de diabetes autorreferido no Brasil: resultados da Pesquisa Nacional de Saúde 2013. Epidemiol Serv Saúde. 2015;24:305-14.

20. Malta DC, Oliveira TP, Vieira ML, Almeida L, Szwarcwald CL. Uso e exposição à fumaça do tabaco no Brasil: resultados da Pesquisa Nacional de Saúde 2013. Epidemiol Serv Saúde. 2015;24:239-48.

21. Malta DC, Iser BPM, Claro RM, Moura LD, Bernal RTI, Nascimento AF, et al Prevalência de fatores de risco e proteção para doenças crônicas não transmissíveis em adultos: estudo transversal, Brasil, 2011. Epidemiol Serv Saúde. 2013;22:423-34

22. Mohammed S, Van Buren II G, Fisher WE. Pancreatic cancer: Advances in treatment. World J Gastroenterol. 2014;20:9354-60.

23. Chang JC, Kundranda M. Novel Diagnostic and Predictive Biomarkers in Pancreatic Adenocarcinoma. Int J Mol Sci. 2017;18:667.

24. Curado MP, de Souza DLB. Cancer burden in Latin America and the Caribbean. Ann Glob Health. 2014;80:370-7.

25. Barbosa IR, de Souza DLB, Bernal MM, Costa ICC. Desigualdades regionais na mortalidade por câncer de colo de útero no Brasil: tendências e projeções até o ano 2030. Ciência \& Saúde Coletiva, 2016;21:253-62.

26. Jerez-Roig J, Souza DL, Medeiros PF, Barbosa IR, Curado MP, Costa IC, Lima KC. Future burden of prostate cancer mortality in Brazil: a population-based study. Cadernos de Saúde Pública. 2014;30:2451-8.

27. Joliat GR, Hahnloser D, Demartines N, Schäfer M. Future development of gastrointestinal cancer incidence and mortality rates in Switzerland: a tumour registry-and population-based projection up to 2030. Swiss Med Wkly. 2015;145:w14188.

28. Rahib L, Smith BD, Aizenberg R, Rosenzweig AB, Fleshman JM, Matrisian LM. Projecting cancer incidence and deaths to 2030: the unexpected burden of thyroid, liver, and pancreas cancers in the United States. Cancer Res. 2014;74:2913-21.

29. Knaul FM, Alleyne G, Piot P, Atun R, Gralow JR, Neal C, et al. Health system strengthening and cancer: a diagonal response to the challenge of chronicity. In: Knaul FM, Gralow JR, Atun R, Bhadelia A, editors. Closing the cancer divide: an equity imperative. Cambridge: Harvard Global Equity Initiative; 2012. p. 79-95.

30. Chatenoud L, Bertuccio P, Bosetti C, Levi F, Curado MP, Malvezzi M, et al. Trends in cancer mortality in Brazil, 1980-2004. Eur J Cancer Prev. 2010;19:79-86. 